\title{
Prognostic value of cancer stem cell marker CD133 expression in esophageal carcinoma: A meta-analysis
}

\author{
YUN-PENG SUI, XUE-PING JIAN, LI MA, GUI-ZHEN XU, HUAI-WEI LIAO, \\ YAN-PING LIU and HUI-CAI WEN
}

Department of Plastic Surgery, The First Affiliated Hospital of Nanchang University, Nanchang, Jiangxi 330006, P.R. China

Received February 19, 2015; Accepted September 8, 2015

DOI: $10.3892 / \mathrm{mco} .2015 .651$

\begin{abstract}
CD133 has been identified as a putative neoplastic stem cell marker in esophageal carcinoma. However, the prognostic value of CD133 overexpression in patients with esophageal carcinoma remains controversial. A meta-analysis of previous studies was performed, in order to assess the association of CD133 overexpression with the clinicopathological characteristics of esophageal carcinoma patients. A total of 7 studies, including 538 patients, were subjected to the final analysis. Our results indicated that a positive CD133 expression was significantly associated with lymph node metastasis [odds ratio $(\mathrm{OR})=3.09,95 \%$ confidence interval $(\mathrm{CI}): 1.93-4.95$; $\mathrm{P}<0.00001]$, clinical stage $(\mathrm{OR}=4.26$, 95\% CI: $1.55-11.73 ; \mathrm{P}=0.005)$ and histopathological grade $(\mathrm{OR}=2.40$, 95\% CI: 1.16-4.94; $\mathrm{P}=0.02)$. There was no statistically significant association of CD133 with depth of invasion $(\mathrm{OR}=1.89$, 95\% CI: 0.42-8.43; $\mathrm{P}=0.41)$. Based on the results of this study, we concluded that CD133 is an efficient prognostic factor in esophageal carcinoma. Higher CD133 expression is significantly associated with lymph node metastasis, clinical stage and histopathological grade.
\end{abstract}

\section{Introduction}

Esophageal carcinoma is the sixth most common cause of cancer-related mortality, with an incidence in China accounting for $50 \%$ of the cases worldwide (1). Although chemotherapy, radiotherapy, surgery and biologically targeted therapies continue to progress, the prognosis of esophageal carcinoma patients remains poor, with a 5-year survival rate of $<20 \%$ worldwide (2). Accumulating evidence indicates that cancer cells with stem cell-like properties have a potential for self-renewal and differentiation, thereby driving tumorigenesis, resistance to chemotherapy and/or radiotherapy (3). Due

Correspondence to: Professor Hui-Cai Wen, Department of Plastic Surgery, The First Affiliated Hospital of Nanchang University, 17 Yongwaizheng Street, Nanchang, Jiangxi 330006, P.R. China E-mail:whcjxmc@163.com

Key words: esophageal carcinoma, cancer stem cells, CD133, clinicopathological characteristics, prognosis, meta-analysis to the existence of cancer stem cells, conventional therapies may not be able to effectively eliminate these cancer cells. Therefore, novel biomarkers must be identified to improve the prognosis of esophageal carcinoma. Recently, certain cell surface markers have been identified as stem cell markers in cancer; among these, CD133 is considered to be the most robust surface marker for cancer stem cells to date.

CD133, also known as prominin-1, is a member of the pentaspan transmembrane glycoprotein family (4). The $\mathrm{CD}_{133}{ }^{+}$phenotype was first used to identify and isolate malignant brain tumor stem cells. CD133 is currently identified as a cancer stem cell marker in various solid tumors, such as hepatocellular carcinoma (5), ovarian (6), colon (7) and esophageal carcinoma (8). Zimmerer et al (9) reported that as few as $500 \mathrm{CD} 133^{+}$melanoma cells were able to form a tumor in NOD/SCID mice, whereas 100,000 CD133- cells failed to do so; in addition, Taxol induced apoptosis in CD133- cells, but not in $\mathrm{CD}_{133^{+}}$cells. These findings suggested that cancer stem cells have the ability to form the bulk of a tumor cell population and confer resistance to conventional therapy.

As regards esophageal carcinoma, the correlation between CD133 expression and the clinicopathological parameters of esophageal carcinoma is relatively unclear. In order to address these issues, we performed a meta-analysis to determine the association between CD133 expression and the clinicopathological characteristics of esophageal carcinoma.

\section{Materials and methods}

Publication search. We performed a comprehensive search through Web of Science, PubMed and the China National Knowledge Infrastructure (CNKI) databases for relevant articles using the following keywords: (CD133 or prominin or $\mathrm{AC133}$ ) and (outcome or survival or prognosis) and (esophageal carcinoma or esophageal cancer) and (neoplastic stem cells or cancer stem cell or tumor-initiating cell), up to January 3, 2015. A manual search was also performed through the bibliographies of relevant articles to identify studies potentially eligible for inclusion. The title and abstract of each study identified in the search was scanned to exclude any clearly irrelevant articles.

Inclusion criteria. The following criteria were adopted for the included studies: i) Diagnosis of esophageal carcinoma was proven by histopathological methods; ii) the studies investigated 
Table I. Characteristics of studies included in the meta-analysis.

\begin{tabular}{|c|c|c|c|c|c|c|c|c|c|c|}
\hline $\begin{array}{l}\text { First } \\
\text { author }\end{array}$ & Year & Language & Country & $\begin{array}{c}\text { Tumor stage } \\
\text { (TNM) }\end{array}$ & $\begin{array}{c}\text { Median age } \\
\text { (years) }\end{array}$ & $\begin{array}{l}\text { Histopathological } \\
\text { type }\end{array}$ & Technique & $\begin{array}{l}\text { No. of } \\
\text { patients }\end{array}$ & Site & (Refs.) \\
\hline Yang & 2010 & Chinese & China & I-IV & 52.8 & SCC & IHC & 90 & $\begin{array}{c}\text { Esophagus } \\
\text { or bone }\end{array}$ & (10) \\
\hline $\mathrm{Cao}$ & 2009 & Chinese & China & II-III & 54.3 & SCC & IHC & 68 & $\begin{array}{c}\text { Esophagus } \\
\text { or bone }\end{array}$ & (11) \\
\hline Fei & 2011 & Chinese & China & I-IV & 55.4 & SCC & IHC & 90 & $\begin{array}{l}\text { Esophagus } \\
\text { or liver }\end{array}$ & (12) \\
\hline Feng & 2014 & Chinese & China & I-IV & 68.8 & $\mathrm{SCC}$ & IHC & 28 & $\begin{array}{c}\text { Esophagus } \\
\text { or bone }\end{array}$ & (13) \\
\hline Wang & 2014 & Chinese & China & I-IV & 69 & SCC & IHC & 40 & $\begin{array}{c}\text { Esophagus } \\
\text { or brain }\end{array}$ & (14) \\
\hline Okamoto & 2013 & English & Japan & I-IV & 56.1 & SCC & IHC & 86 & $\begin{array}{c}\text { Esophagus } \\
\text { or brain }\end{array}$ & (15) \\
\hline Peng & 2012 & Chinese & China & III & 58 & SCC & IHC & 136 & $\begin{array}{c}\text { Esophagus } \\
\text { or liver }\end{array}$ & (16) \\
\hline
\end{tabular}

TNM, tumor-node-metastasis; SCC, squamous cell carcinoma; IHC, immunohistochemistry.

CD133 expression in primary esophageal carcinoma tissues (obtained surgically or bioptically); iii) the association between CD133 expression and clinicopathological parameters or prognosis was analyzed; iv) the studies were published as full articles in English or Chinese; and v) the articles were published as original research. Reviews, comments, duplicated studies and articles unrelated to our analysis were excluded.

Data extraction. All the data were extracted by two investigators independently. If an agreement could not be reached, an expert was invited to the discussion. Data tables were drawn to extract all relevant data from texts, tables and figures of the included papers, including first author's name, year of publication, patient's country, tumor stage, number of patients, research technique used, histopathological type and tumor location.

Statistical analysis. A meta-analysis was conducted of the data collected by using Review Manager 5.2 software. The P-values were two-sided, with the significance level set at $\mathrm{P}<0.05$. Odds ratios (ORs) with $95 \%$ confidence intervals (CIs) were used to evaluate the association between the expression of the stem cell marker CD133 and the clinicopathological parameters of esophageal carcinoma, including lymph node metastasis, clinical stage, histopathological grade and depth of invasion. Heterogeneity across studies was evaluated using the Q-test and P-values. ORs were calculated using a random-effects model when the P-value was $<0.05$. Otherwise, a fixed-effects model was used. Egger's funnel plots were used to assess publication bias using Stata 13.0 software (StataCorp LP, College Station, TX, USA). $\mathrm{P}<0.05$ was considered to be representative of statistically significant publication bias.

\section{Results}

Study characteristics. The characteristics of the eligible studies are summarized in Table I. A total of 7 studies, published between 2009 and 2014, met the inclusion criteria for this metaanalysis (Fig. 1). The total number of patients was 538, ranging from 28 to 136 patients per study. All the studies were based on the data of retrospective analyses. A total of 5 studies reported the association between CD133 expression and lymph node metastasis; 5 studies reported the association between CD133 expression and clinical stage; 7 studies reported the association between CD133 expression and histopathological grade; and 4 studies reported the association between CD133 expression and depth of invasion. Immunohistochemistry (IHC) was used to evaluate CD133 expression in esophageal carcinoma specimens in all the studies.

\section{Main results of the meta-analysis}

Correlation of CD133 with lymph node metastasis. A total of 5 studies assessed the association between CD133 expression and lymph node metastasis (Fig. 2). A positive CD133 expression was significantly associated with lymph node metastasis (OR=3.09, 95\% CI: 1.93-4.95; $\mathrm{P}<0.00001)$, without any heterogeneity in the data $\left(\chi^{2}=5.58, \mathrm{I}^{2}=28 \% ; \mathrm{P}=0.23\right)$. These studies indicated that CD133 overexpression is associated with the prognosis of esophageal carcinoma.

Correlation of CD133 with clinical stages. A total of 5 studies assessed the association between CD133 expression and clinical stage (Fig. 3). A positive CD133 expression was significantly associated with clinical stage $(\mathrm{OR}=4.26$, 95\% CI: $1.55-11.73 ; \mathrm{P}=0.005)$, with heterogeneity in the data $\left(\chi^{2}=13.84, \mathrm{I}^{2}=71 \% ; \mathrm{P}=0.008\right)$. In order to test the heterogeneity in clinical stage, we performed sensitivity analyses to assess the stability of the results. Our results suggested that the sensitivity was low and the results were more robust and credible. These studies indicated that CD133 overexpression is associated with the prognosis of esophageal carcinoma.

Correlation of CD133 with histopathological grade. A total of 7 studies assessed the association between CD133 expression and histopathological grade (Fig. 4). There was 


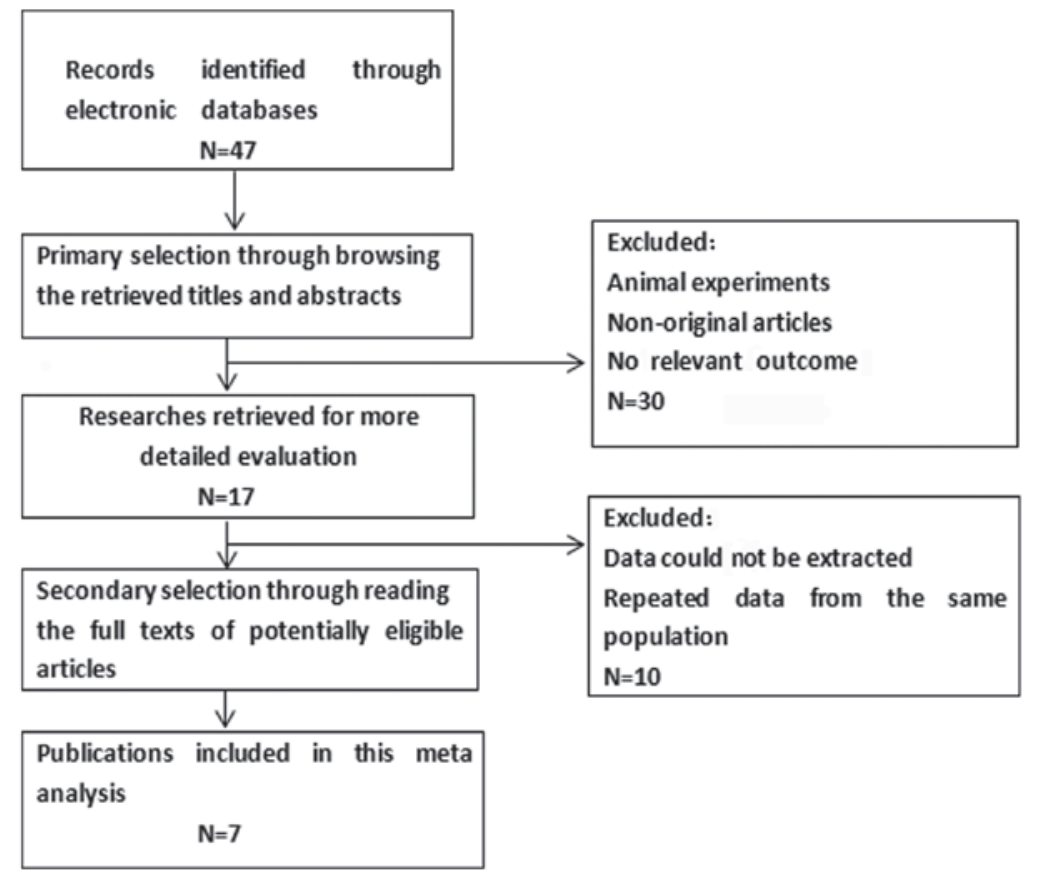

Figure 1. Flow chart of the study selection process.

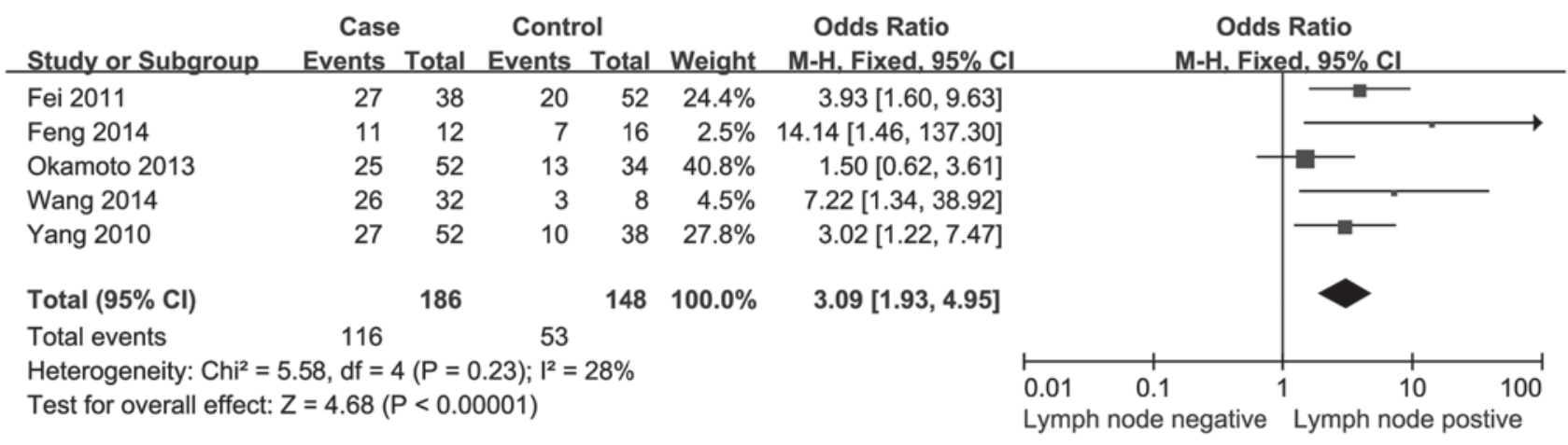

Figure 2. Forest plot of ORs for the association of CD133 expression with lymph node metastasis. OR, odds ratio; CI, confidence interval.

\begin{tabular}{|c|c|c|c|c|c|c|c|c|c|c|}
\hline Study or Subgroup & $\begin{array}{r}\text { Case } \\
\text { Events }\end{array}$ & Total & $\begin{array}{l}\text { Contrc } \\
\text { Events }\end{array}$ & & Weight & $\begin{array}{c}\text { Odds Ratio } \\
\text { M-H, Random, } 95 \% \mathrm{Cl}\end{array}$ & & $\begin{array}{r}\text { Odds } \\
M-H, \text { Rand }\end{array}$ & $\begin{array}{l}\text { Ratio } \\
\text { lom, } 95 \% \mathrm{Cl}\end{array}$ & \\
\hline Cao 2009 & 33 & 45 & 12 & 23 & $22.7 \%$ & $2.52[0.88,7.22]$ & & & & \\
\hline Fei 2011 & 26 & 45 & 21 & 45 & $25.0 \%$ & $1.56[0.68,3.60]$ & & & & \\
\hline Feng 2014 & 11 & 13 & 2 & 15 & $13.0 \%$ & $35.75[4.30,297.26]$ & & & & $\rightarrow$ \\
\hline Wang 2014 & 9 & 11 & 20 & 29 & $16.1 \%$ & $2.02[0.36,11.34]$ & & & & \\
\hline Yang 2010 & 28 & 40 & 9 & 50 & $23.3 \%$ & $10.63[3.95,28.57]$ & & & & \\
\hline Total $(95 \% \mathrm{Cl})$ & & 154 & & 162 & $100.0 \%$ & $4.26[1.55,11.73]$ & & & & \\
\hline Total events & 107 & & 64 & & & & & & & \\
\hline \multicolumn{7}{|c|}{$\begin{array}{l}\text { Heterogeneity: } \mathrm{Tau}^{2}=0.89 ; \mathrm{Chi}^{2}=13.84, \mathrm{df}=4(\mathrm{P}=0.008) ; \mathrm{I}^{2}=71 \% \\
\text { Test for overall effect: } Z=2.81(P=0.005)\end{array}$} & 0.01 & $\begin{array}{l}0.1 \\
\text { TNM I - II }\end{array}$ & $\begin{array}{c}10 \\
\text { TNM III-IV }\end{array}$ & 100 \\
\hline
\end{tabular}

Figure 3. Forest plot of ORs for the association of CD133 expression with clinical stage. OR, odds ratio; CI, confidence interval.

a significant difference between the well- and moderately differentiated esophageal carcinoma group and the poorly differentiated esophageal carcinoma group $(\mathrm{OR}=2.40$, 95\% CI: 1.16-4.94; $\mathrm{P}=0.02)$, with heterogeneity in the data $\left(\chi^{2}=14.75, \mathrm{I}^{2}=59 \% ; \mathrm{P}=0.02\right)$. In order to test the heterogeneity in histopathological grade, we performed sensitivity analyses to assess the stability of the results. Our results suggested that the results were more robust and credible.

Correlation of CD133 with depth of invasion. A total of 4 studies assessed the association between CD133 expression 




Figure 4. Forest plot of ORs for the association of CD133 expression with histopathological grade. OR, odds ratio; CI, confidence interval.

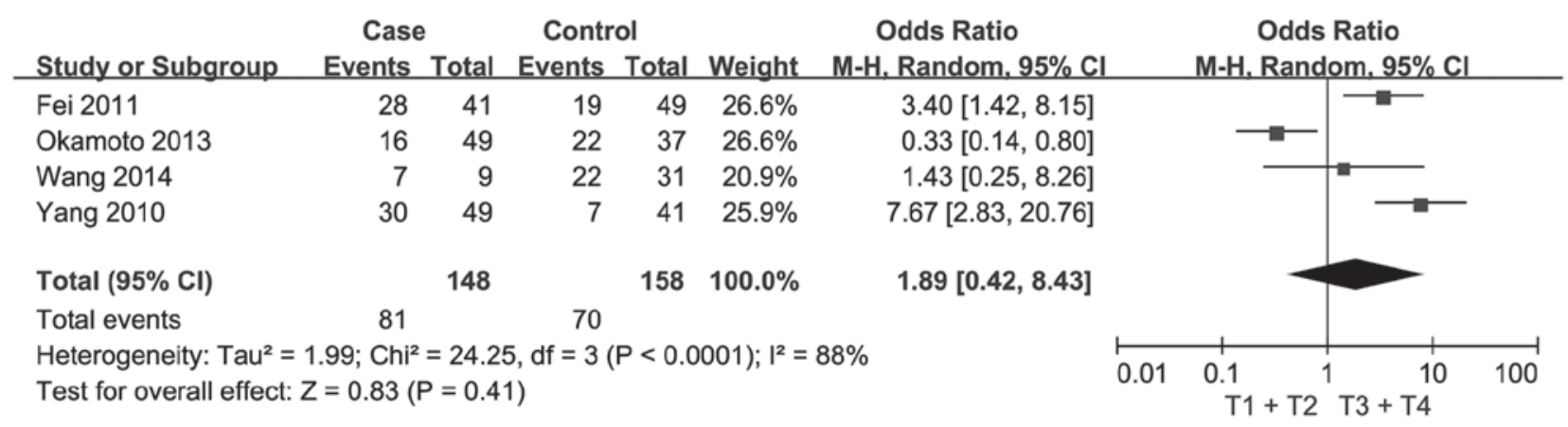

Figure 5. Forest plot of ORs for the association of CD133 expression with depth of invasion. OR, odds ratio; CI, confidence interval.

and depth of invasion (Fig. 5). There were no significant differences in the depth of invasion (OR=1.89, 95\% CI: 0.42-8.43; $\mathrm{P}=0.41$ ) between different expression groups, indicating that higher CD133 expression was not significantly associated with depth of invasion in esophageal carcinoma.

Publication bias. Egger's tests were applied to estimate the publication bias of the included studies (Fig. 6) and did not reveal any evidence of obvious asymmetry in the overall meta-analysis of all the included studies.

\section{Discussion}

Esophageal carcinoma is one of the most common and most aggressive cancers worldwide and a leading cause of cancer-related mortality in China (17). Surgical resection, which achieves long-term survival of esophageal carcinoma patients, is considered to be one of the standard treatments of esophageal carcinoma, provided that the tumor is resectable (18). Although there has been significant progress in the diagnosis and treatment of esophageal carcinoma, its incidence and mortality rates remain high; therefore, new therapies are urgently needed (19). It has been reported that a rare subpopulation of cells with special surface markers within esophageal carcinoma have the potential to initiate and sustain tumor growth. These cells have the exclusive properties of self-renewal and may give rise to all the heterogeneous lineages of cancer cells that eventually constitute the tumor bulk (20). Cancer stem cells were first reported in acute myeloid leukemia, in which a rare subset comprising $0.01-1 \%$ of the total population was able to establish tumors when transplanted into mice with severe combined immunodeficiency (SCID mice), whereas the major cell population could not (21). Since then, cancer stem cells have been reported to promote solid tumor development, including breast cancer (22), melanoma (23), hepatocellular carcinoma (5) and esophageal carcinoma (8). This new paradigm has remarkable implications for cancer therapy, as it suggests that our currently available therapies are more successful at eradicating non-cancer stem cells rather than cancer stem cells $(24,25)$. Cancer stem cells exhibit major phenotypic and functional heterogeneity, which may help distinguish them from cancer cells and may lead to the identification of better targets for therapeutic intervention (26).

Over the last few years, several cell surface markers have been identified as stem cell markers in cancer, including CD133, CD90, CD271, CD44, CD24, ABCB5 and ALDH. CD133 is a widely used marker for isolating cancer stem cells in a range of solid tumors (27). CD133 is a member of the cell membrane protein superfamily and has been used to identify tumor-initiating cells as a specific marker in esophageal carcinoma (28). In addition, it has been reported that the presence of $\mathrm{CD}_{133^{+}}$cells was associated with distinct clinicopathological characteristics in esophageal carcinoma. It is notable that this association was observed in our meta-analysis of CD133 expression with lymph node metastasis, clinical stage and histopathological grade, suggesting that CD133 may be a marker of poor prognosis in esophageal carcinoma. There are also certain shortcomings in this study that ought to be discussed. First, the number of 
$\mathbf{A}$

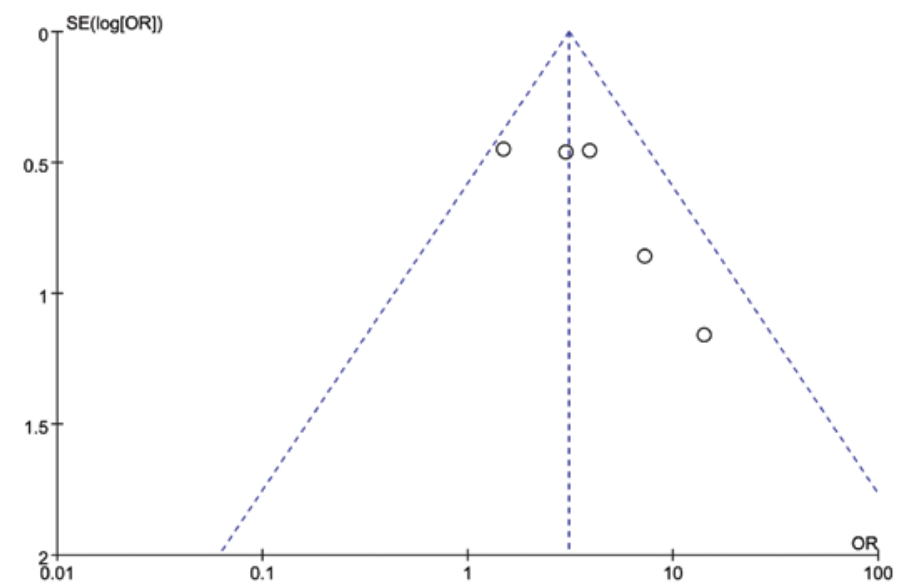

B

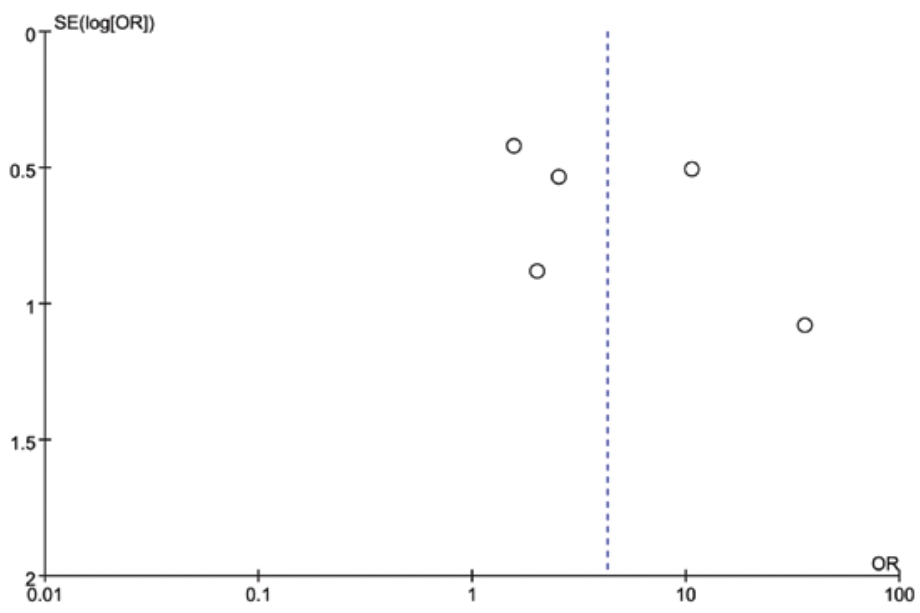

C



D

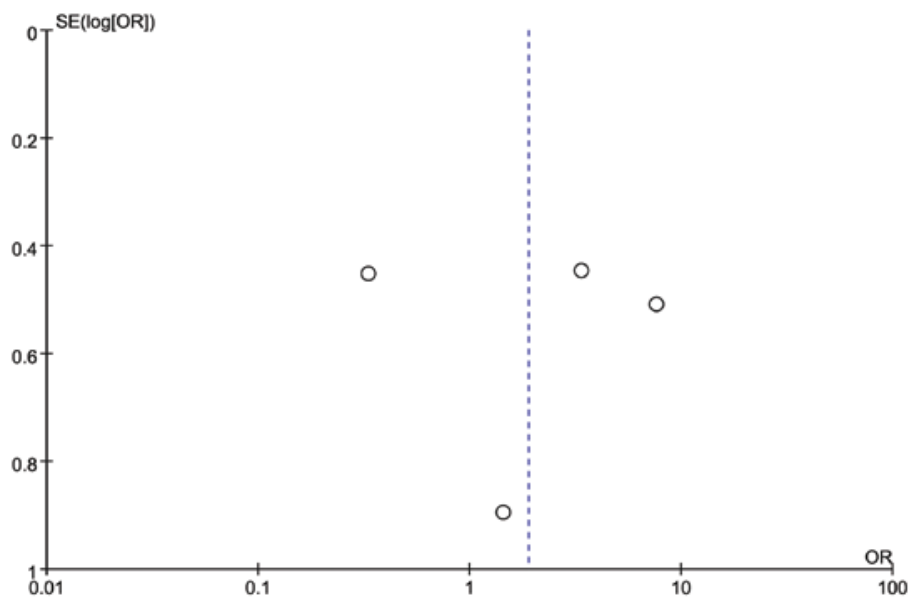

Figure 6. Funnel plot analysis of publication bias for clinicopathological parameters. (A) Lymph node metastasis, (B) clinical stage, (C) histopathological grade and (D) depth of invasion. SE, standard error; OR, odds ratio. 
included studies was relatively small, with only 538 cases in total. Esophageal carcinoma patients had received different treatments (perioperative adjuvant therapy or curative surgical resection alone), and the preoperative TNM stage varied. We were unable to assess these potential confounders present in individual studies. Second, potential publication bias was a major concern. We restricted our systematic review to articles published in English or Chinese, as other languages were not accessible to the readers. Third, in the meta-analyses of prognostic factors, variability in definitions, outcomes, measurements and experimental procedures may contribute to between-study heterogeneity (29).

In conclusion, despite the abovementioned limitations, this meta-analysis indicated that CD133 expression was associated with the clinical parameters of esophageal carcinoma, such as lymph node metastasis, clinical stage and histopathological grade. Further studies on CD133 and its potential as a marker for esophageal carcinoma prognosis in clinical practice are required.

\section{References}

1. Shi HY, Zhu SC, Shen WB and Liu ML: Pathological characteristics of esophageal cancer. Oncol Lett 8: 533-538, 2014.

2. Tomochika S, Iizuka N, Watanabe Y, Tsutsui M, Takeda S, Yoshino S, Ichihara K and Oka M: Increased serum cell-free DNA levels in relation to inflammation are predictive of distant metastasis of esophageal squamous cell carcinoma. Exp Ther Med 1: 89-92, 2010.

3. Tan Y, Chen B, Xu W, Zhao W and Wu J: Clinicopathological significance of CD133 in lung cancer: A meta-analysis. Mol Clin Oncol 2: 111-115, 2014.

4. He A, Qi W, Huang Y, Feng T, Chen J, Sun Y, Shen Z and Yao Y: CD133 expression predicts lung metastasis and poor prognosis in osteosarcoma patients: A clinical and experimental study. Exp Ther Med 4: 435-441, 2012.

5. Bodzin AS, Wei Z, Hurtt R, Gu T and Doria C: Gefitinib resistance in HCC Mahlavu cells: Upregulation of CD133 expression, activation of IGF-1R signaling pathway, and enhancement of IGF-1R nuclear translocation. J Cell Physiol 227: 2947-2952, 2012.

6. Ferrandina G, Bonanno G, Pierelli L, Perillo A, Procoli A, Mariotti A, Corallo M, Martinelli E, Rutella S, Paglia A, et al: Expression of CD133-1 and CD133-2 in ovarian cancer. Int J Gynecol Cancer 18: 506-514, 2008.

7. Kojima M, Ishii G, Atsumi N, Fujii S, Saito N and Ochiai A: Immunohistochemical detection of CD133 expression in colorectal cancer: A clinicopathological study. Cancer Sci 99: $1578-1583,2008$

8. Hang D, Dong HC, Ning T, Dong B, Hou DL and Xu WG: Prognostic value of the stem cell markers CD133 and ABCG2 expression in esophageal squamous cell carcinoma. Dis Esophagus 25: 638-644, 2012.

9. Zimmerer RM, Korn P, Demougin P, Kampmann A, Kokemüller H, Eckardt AM, Gellrich NC and Tavassol F: Functional features of cancer stem cells in melanoma cell lines. Cancer Cell Int 13: 78, 2013.

10. Yang AP: The expression of marker cancer stem cells CD133 and Musashi-1 in human esophageal carcinoma and its clinical significances. Southeast Univ 15: 698, 2010 (In Chinese).
11. Cao YK: Relationship between CD133 expression and chemoradio therapy response in esophageal squamous cell carcinoma. Zhongshan Univ 16: 75, 2009 (In Chinese).

12. Fei ZH, Chen SX and Chen L: Expression and significance of Bmi-1 and CD133 in esophageal squamous cell carcinoma. Mod Pract Med 23: 337, 2011 (In Chinese).

13. Feng KX, Li SP, Liu XL, Zhou J, Yuan S, Xie MH, Jing DS and Sun YZ: Expression of NF- $\kappa \mathrm{B}, \mathrm{CD} 133$ in esophageal cancer and correlation with metastasis. Mod Oncol 23: 0206, 2014 (In Chinese).

14. Wang YW, Zhang $\mathrm{J}$ and Feng G: Expression of CD133 in esophageal squamous cell carcinoma and its clinical significance. Shaanxi Med J 43: 1464, 2014 (In Chinese).

15. Okamoto H, Fujishima F, Nakamura Y, et al: Significance of CD133 expression in esophageal squamous cell carcinoma. World J Surg Oncol 11: 51, 2013 (In Chinese).

16. Peng J, Guo JJ, Ao X, Zhou TJ, Wang M, Li YQ and Zhang HZ: Expression of CD133 in the tissue of locally advanced esophagus squamous cell cancer patients and its significance. Chin J Exp Surg 29: 541, 2012 (In Chinese).

17. Ning Z, Zhu H, Li F, Liu Q, Liu G, Tan T, Zhang B, Chen S, Li G, Huang D, et al: Tumor suppression by miR-31 in esophageal carcinoma is p21-dependent. Genes Cancer 5: 436-444, 2014.

18. Rios-Galvez S, Meixueiro-Daza A and Remes-Troche JM Achalasia: a risk factor that must not be forgotten for esophageal squamous cell carcinoma. BMJ Case Rep 2015: pii: bcr2014204418, 2015.

19. Shimizu Y, Takahashi M, Mizushima T, Ono S, Mabe K, Ohnishi S, Kato M, Asaka M and Sakamoto N: Chromoendoscopy with iodine staining, as well as narrow-band imaging, is still useful and reliable for screening of early esophageal squamous cell carcinoma. Am J Gastroenterol 110: 193-194, 2015.

20. Nguyen LV, Vanner R, Dirks P and Eaves CJ: Cancer stem cells: An evolving concept. Nat Rev Cancer 12: 133-143, 2012.

21. Bonnet D and Dick JE: Human acute myeloid leukemia is organized as a hierarchy that originates from a primitive hematopoietic cell. Nat Med 3: 730-737, 1997.

22. Al-Hajj M, Wicha MS, Benito-Hernandez A, Morrison SJ and Clarke MF: Prospective identification of tumorigenic breast cancer cells. Proc Natl Acad Sci USA 100: 3983-3988, 2003.

23. Klein WM, Wu BP, Zhao S, Wu H, Klein-Szanto AJ and Tahan SR: Increased expression of stem cell markers in malignant melanoma. Mod Pathol 20: 102-107, 2007.

24. Lobo NA, Shimono Y, Qian D and Clarke MF: The biology of cancer stem cells. Annu Rev Cell Dev Biol 23: 675-699, 2007.

25. Vermeulen L, Sprick MR, Kemper K, Stassi G and Medema JP: Cancer stem cells - old concepts, new insights. Cell Death Differ 15: 947-958, 2008.

26. Liu S, Liu C, Min X, Ji Y, Wang N, Liu D, Cai J and Li K: Prognostic value of cancer stem cell marker aldehyde dehydrogenase in ovarian cancer: A meta-analysis. PLoS One 8: e81050, 2013.

27. Visvader JE and Lindeman GJ: Cancer stem cells in solid tumours: Accumulating evidence and unresolved questions. Nat Rev Cancer 8: 755-768, 2008.

28. Yao Q, Sun JG, Ma H, Zhang AM, Lin S, Zhu CH, Zhang T and Chen ZT: Monitoring microRNAs using a molecular beacon in CD133 ${ }^{+} \mathrm{CD}_{338^{+}}$human lung adenocarcinoma-initiating A549 cells. Asian Pac J Cancer Prev 15: 161-166, 2014.

29. Simon R and Altman DG: Statistical aspects of prognostic factor studies in oncology. Br J Cancer 69: 979-985, 1994. 